Ann. Biol. anim. Bioch. Biophys., I964, 4 (I), 95-97

\title{
MODES D'EXPRESSION DE L'AJUSTEMENT DES BESOINS ENERGETIQUE ET AZOTÉ CHEZ LE POUSSIN
}

\author{
J. GUILLAUME et M. FENDRY \\ Station de Recherches avicoles, \\ Centre national de Recherches zootechniques, Jouy-en-Josas (Seine-et-Oise)
}

SOMMAIRE

En alimentation séparée, le taux protidique du repas reconstitué par le poussin est une fonction linéaire de la quantité de protides qui lui est allouée.

Les travaux poursuivis par CALET, JOUANDET et BARATou, I96I, chez le poussin puis repris chez le Rat par HENRY et RÉRAT (I962) RÉRAT et HENRY (I963) et Peretianu et Abraham (i963), ont montré que l'on pouvait avantageusement utiliser l'alimentation séparée pour nourrir les animaux dans des buts expérimentaux. Pour cela on leur donne simultanément, mais dans deux mangeoires distinctes, une ration protidique limitée en quantité et un repas protéiprive ad libitum. L'animal ajuste alors spontanément son ingéré énergétique à la qualité et à la quantité des protides alloués.

Le nombre de calories consommées spontanément par le poussin et la quantité de protéines qu'il reçoit sont dans un certain rapport, - qui n'est autre que le rapport $\frac{\text { Calories }}{\text { Protéines }}-$ dont la valeur optimale est fonction des protides alimentaires.

On peut envisager un autre mode d'expression des phénomènes de régulation dont nous venons de parler : en additionnant les quantités consommées de chacun des repas, on reconstitue un régime complet dont on peut calculer le taux protidique. 
Nous avons effectué trois expériences en alimentation séparée sur des poussins d'âge voisin ( 3 à 4 semaines) mais de souches différentes. Les protides choisis dans un large éventail de provenance possédaient des efficacités très diverses ; ils étaient distribués à raison de $\mathrm{I} g$ à $20 \mathrm{~g} / \mathrm{jour}$.

Les figures I et 2 illustrent les variations du taux protidique calculé comme nous l'avons indiqué plus haut en fonction de la ration journalière de protéines.
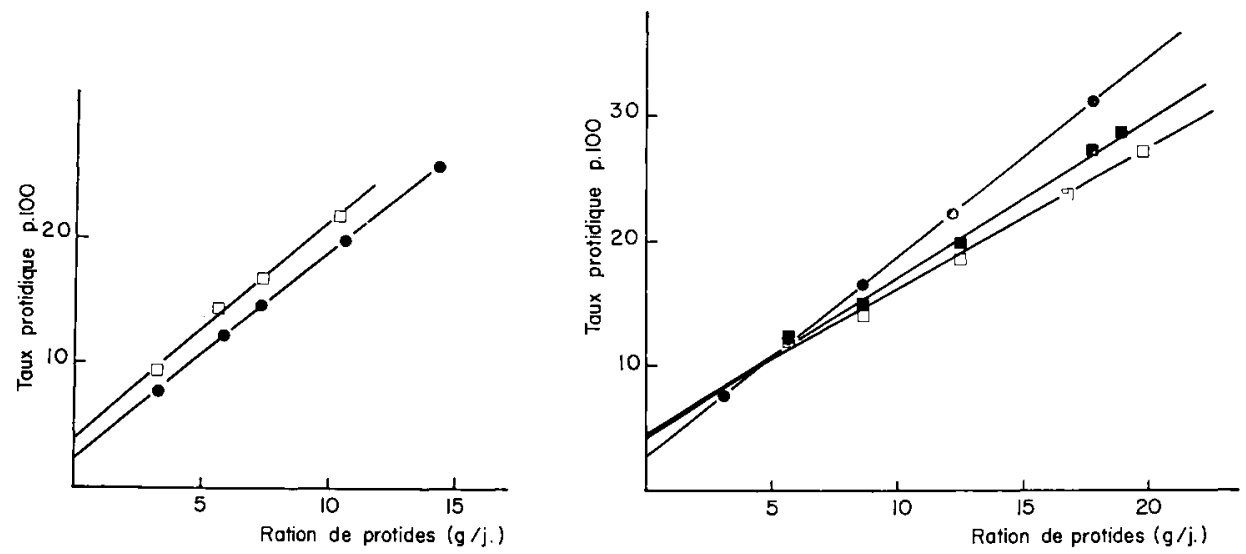

FIG. I. - Influence de la valeur biologique

Poussin Rhode Islande Red $\times$ Wyandotte de 28 jours - Durée 30 jours

- Mélange de farine poisson - gluten $=80 \mathrm{p}$. $100-20 \mathrm{p} \cdot 100$

$$
r=0,999 \quad \mathrm{~T}=2,575+(\mathrm{r}, 664 \pm 0,0 \mathrm{Ir}) q
$$

$\square$ Mélange de farine poisson - gluten $=20 \mathrm{p} .100-80 \mathrm{p} \cdot 100$

$$
r=0,990 \quad \mathrm{~T}=4, \mathrm{I} 87+(\mathrm{r}, 750 \pm 0,056) q
$$

Fis. 2. - Infuence de l'âge

Poussins Arbor Acre de 28 jours - Duré 20 jours.

Mélange de poisson -c caséine - tourteau de sésame

$$
\begin{aligned}
& \bullet \mathrm{I}^{\mathrm{re}} \text { semaine d'expérience } \\
& r=0,999 \mathrm{~T}=2,886+\mathrm{I}, 590( \pm 0,0085) q \\
& \quad 2^{2} \text { semaine d'expérience } \\
& r=0,998 \quad \mathrm{~T}=4,220+\mathrm{I}, 285( \pm 0,042) q \\
& \square 3^{\mathrm{e}} \text { semaine d'expérience } \\
& r=0,999 \quad \mathrm{~T}=4,875+\mathrm{I}, \mathrm{I} 26( \pm 0,03 \mathrm{I}) q
\end{aligned}
$$

Bien que RÉRAT et HENRY, (I963), aient fait allusion partiellement à ces phénomènes, il convient de les souligner et d'en tirer quelques conclusions :

$\left.I^{0}\right)$ La relation d'ajustement du taux proditique à la quantité de protéines est rigoureusement linéaire ( $r$ allant de 0,990 o à 0,9999 ), sauf pour les plus faibles quantités de protides ( $\mathrm{à} 3 \mathrm{~g}$ par jour suivant la valeur biologique).

$2^{\circ}$ ) Pour l'ensemble des périodes expérimentales la pente des droites est pratiquement indépendante de la valeur biologique des protides, les différences de pente ne sont en effet pas significatives. Par contre, pour chaque dose de matières azotées ingérées, le pourcentage de protéines du régime établi par le poussin est d'autant plus élevé que celles-ci sont moins efficaces.

$\left.3^{\circ}\right)$ Au fur et à mesure que le poussin vieillit, la pente des droites diminue régu- 
lièrement. L,es poussins les plus âgés consomment toujours la plus forte quantité d'aliment non azoté pour une même ration de protéines.

Dans les différentes conditions où nous nous sommes placés, la relation entre la consommation de calories et la quantité de protides ingérée est une fonction complexe qu'il est difficile de mettre directement en équation. On peut cependant y parvenir indirectement en utilisant le mode d'expression que nous venons d'étudier. La relation donnant le taux protidique du repas reconstitué en fonction de la dose des protides est une droite. Cette droite nous permet de prévoir l'allure des courbes de régression de la consommation totale d'énergie sur la quantité de protides ingérés ou du rapport $\frac{\text { Calories }}{\text { Protéines }}$ sur cette même quantité. Dans le premier cas il s'agit d'une hyperbole, dans le second cas d'une courbe du troisième degré.

Reçu pour publication en mars 1964.

\author{
SUMMARY
}

METHODS OF EXPRESSING THE ADJUSTMENT OF REQUIREMENTS FOR ENERGY AND PROTEIN IN THE CHICKEN.

When chickens are given a limited amout of protein and protein-free feed in two separate feeders the proteins contents of the total diet which they choose increases linearly; with the amount of protein offered. Figures $I$ and 2 show the influence of the biological value and the age of the birds on the parameters of the lines of the graph. From these lines equations may be derived relating the intake of feed or the ratio of energy to protein to the intake of protein.

\title{
RÉFÉRENCES BIBLIOGRAPHIQUES
}

Calet C., Joundet C., Baratou J., ig61. Variation de la consommation spontanée d'énergie du poussin en fonction de la nature des matières azotées du régime. Ann. Biol. anim. Bioch. Biophys., 1, 5-9.

HENRY Y., RÉrat A., I962. Influence de la qualité et la quantité des matières azotées ingérées sur la consommation spontanée d'énergie chez le Rat en croissance. Ann. Biol. anim. Bioch. Biophys., 2, 267-276

Peretiand J., Abraham J., ig63. Nouvelle technique de mesure du coefficient d'efficacité protéique Ann. Nutr. Alim., 1\%, 8I-102.

Rérat A., Henry Y., ig63. Étude de l'ajustement de la consommation spontanée d'énergie en fonction de l'apport azoté chez le rat en croissance. Ann. Bioch. anim. Bioch. Biophy's., 3, 263-298. 